\title{
The Influence of Space Charge on the Insulation Failure of DC Cable and Its Mechanism Study
}

\author{
Jian DI ${ }^{1, a}$, Wen-Jie MEI ${ }^{1, b,{ }^{*}}$, Wen-Lin PAN ${ }^{1}$, Guang-Hui SONG ${ }^{1}$ and Xing-Li \\ QIN ${ }^{1}$ \\ ${ }^{1}$ Hengtong Submarine Power Cable Co., Ltd, Suzhou, China \\ adijian3658@sina.com,b892897377@qq.com
}

${ }^{*}$ Corresponding author

\begin{abstract}
Keyword: Insulation materials, Space charge, Blending modification, Grafting special functional group modification, Nano-particle modification, mechanism
\end{abstract}

\begin{abstract}
Flexible DC cable has been more and more extensive research, compared to the AC cable, the effect of space charge on the insulation failure of DC cable is more significant. This paper summarized three methods to improve the space charge of insulating materials, namely: nanopartice modification, grafting special functional group modification and blending modification, the analysis shows that nano-particle modification and grafting special functional group modification method are better than the blending modification method in improving the electrical properties of insulating material. This paper has also discussed mechanism of the three modification methods, the modification of nano-particles and the modification of grafting special functional groups both can form traps in the insulation materials, limit the movement of space charge, but two methods will be affected by the grafting rate and dispersion and these in not good to control in the actual production process. The difference is that the special functional groups will also play the role of charge donor, to increase the space charge. The presence of nano-particle size effect, resulting in easy agglomeration of polymer, and the two modified methods will be further verified in the development process of DC $500 \mathrm{kV}$ cable.
\end{abstract}

\section{Introduction}

The DC electricity transmission has the advantages of low loss, easy to non-synchronous interconnection with the power grid and good economy efficiency when transmitting high voltage electricity power in long-distance and with the technical problem of pulse width modulation (PWM) and voltage source converter solved. In addition, with the rise of wind energy, solar energy and other new energy generation, flexible DC transmission technology receives more and more attention, especially when the international energy Internet construction more and more in depth [1], But the research on space charge of HVDC cable is less than HVAC cable, DC cable is easier to accumulate space charge and eventually lead to distortion of local electric field [2], this is also the main cause of cable damage. This paper mainly introduces the influence of space charge on insulation of DC cable, the research progress of DC insulation material and the inhibition mechanism of space charge.

\section{The Influence of Space Charge on DC Cable Insulation}

Space charge is refers to the insulator or semiconductor local area, There are net positive or negative charges on the heterogeneous phase and electrode - dielectric interface [3], mainly produced by the decomposition of crosslinking outgrowth and metal conductor injection. During operation of the cable, the conductor heats up, leading to the temperature of the inside insulation rising, the temperature will gradually reduce from the inside to outside, due to the insulation resistance has a negative temperature characteristics, the temperature decreases and the resistance increases [4].The electric field intensity increases gradually from high temperature side to low 
temperature side, when the electric field intensity exceeds the threshold value of $\mathrm{PE}$, the greater the field strength, the external surface of the crosslinked polyethylene injected from the electrode more obvious[5]. When the cable is fully loaded, the conductor temperature rises. Because of the negative temperature effect of insulation material, in extreme cases, the electric field intensity of insulation screen is strong, but the electric field intensity of conductor screen is weak, then appear "electric field reversal" [6]. At the same time, the larger temperature difference, the more the space charge of insulation shield is on the low temperature side, large amount of space charge will lead to local electric field distortion. In the process of cross-linking, both $\mathrm{DC}$ and $\mathrm{AC}$ cables will produce space charge due to decomposition of polar groups by crosslinking outgrowth. When the AC cable is running, the voltage polarity at both ends of the insulation changes continuously, so the phenomenon of charge aggregation on insulation outer surface will not occur. Therefore, the influence of space charge on DC cable insulation is greater than that of AC cable, it is more urgent to study how restrain the space charge of DC cable insulation.

\section{Improvement Measures for Space Charge}

There are a lot of measures to improve the space charges, such as the conductor screen can make the electric field well-distributed, reduce the electric field strength and the air gap between the conductor and the insulation layer, improve the cable staring corona and resistance to discharge performance, these facts have proved that it can effectively reduce the space charge injection[2]. This paper mainly introduces the directly improvement of the insulation material, and study how to reduce the space charge in the DC cable insulation and inhibition of space charge accumulation. According to the trap energy level theory, traps can be divided into shallow traps and deep traps, and the deep trap can always capture carriers and inhibit the space charge caused by the accumulation of carriers. Therefore, increasing the trap energy level is considered as an important means to suppress the space charge. Through the research of domestic and foreign scholars, there are three main ways: incorporate nano particle filler, graft modification and blend with polymer[8].

\section{Incorporate Nano Particle Filler}

Nowadays, Xi'an Jiao Tong University and Shanghai Jiao Tong University are focus on the effect of adding nano particle filler to attract the space charges, capture the space charges and disperse evenly space charges in the insulation, then to eliminate the space charges. Xi C [9] effectively reduced the insulation electric field distortion come from the temperature gradient by adding nano particles filler in polymer composites. With the increase of the content of nano particles, the trap density of the composite increases and the adjacent trap traps are superimposed on each other, so that the depth of trap tend to be deeper and the breakdown voltage is increased. Adding nano particle filler can improve space charge distribution and volume resistivity of XLPE [10]. But from the feedback of HV power cable manufacturer, using inorganic nano particles filler modified XLPE may occur to broken the extruder filter. This phenomenon may be due to the agglomeration of nano particles in the polymer material, which will lead to poor flow performance, hard to pass the filter and the extrusion pressure is too large.

\section{Graft Modification}

Switzerland ABB Group, Italy Prysmian Group [11], Austria Borealis and other companies have done lots of research on graft modification technology of polyolefin insulation materials. Grafting of special functional groups of monomer in the polyethylene main chain can provide traps to capture space charge, reduce the space charge accumulation density, thereby effectively improving the electrical properties of cable insulation. In recent years, foreign scholars also have done a lot of research on the monomer types, modification process and space structure of low-density polyethylene (LDPE) graft modification. Through a large number of experiments and analysis, they have made great progress, as shown in Table 1. 
Table1. The effect of LDPE grafted with different monomers on space charge

\begin{tabular}{|c|c|c|c|}
\hline Monomers & $\begin{array}{l}\text { Chemical } \\
\text { structure }\end{array}$ & $\begin{array}{l}\text { Influence of graft ratio } \\
\text { on space charge }\end{array}$ & $\begin{array}{l}\text { Optimum } \\
\text { graft ratio }\end{array}$ \\
\hline $\begin{array}{l}\text { AA[12 15] } \\
\text { Acrylic Acid }\end{array}$ & 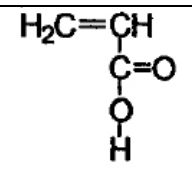 & $\begin{array}{l}\text { Heterocharge increase at first } \\
\text { and then decreases as AA graft } \\
\text { ratio increasing. }\end{array}$ & $>0.135 w t \%$ \\
\hline $\begin{array}{l}\text { MA[15] } \\
\text { Methyl Acrylate }\end{array}$ & & $\begin{array}{l}\text { Heterocharge increase at first } \\
\text { and then decreases as MA graft } \\
\text { ratio increasing. }\end{array}$ & $0.065 \mathrm{wt} \%$ \\
\hline $\begin{array}{l}\text { EA[15] } \\
\text { Ethyl Acrylate }\end{array}$ & $\begin{array}{l}9 \\
\mathrm{C}_{2} \mathrm{H}_{5}\end{array}$ & $\begin{array}{l}\text { Heterocharge increase at first } \\
\text { and then decreases as EA graft } \\
\text { ratio increasing. }\end{array}$ & $0.035 w t \%$ \\
\hline $\begin{array}{l}\text { nBA[12 15] } \\
\text { n-Butyl } \\
\text { Acrylate }\end{array}$ & $\begin{aligned} & \mathrm{H}_{2} \mathrm{C}= \underset{\mathrm{C}}{\mathrm{C}} \mathrm{H} \\
& \stackrel{\mathrm{O}}{\mathrm{O}} \\
& \mathrm{C}_{4} \mathrm{H}_{9}\end{aligned}$ & $\begin{array}{l}\text { Heterocharge increase at first } \\
\text { and then decreases as nBA graft } \\
\text { ratio increasing. }\end{array}$ & $0.058 w t \%$ \\
\hline $\begin{array}{l}\text { MAH[13,16] } \\
\text { Maleic } \\
\text { Anhydride }\end{array}$ & & $\begin{array}{l}\text { Hetercharge decrease with the } \\
\text { increase of MAH graft ratio. }\end{array}$ & $0.17 \sim 0.5 \mathrm{wt} \%$ \\
\hline $\begin{array}{l}\text { VP[17] } \\
\text { 2-Vinylpyridine }\end{array}$ & & $\begin{array}{l}\text { Homocharge decrease with the } \\
\text { increase of VP graft ratio. }\end{array}$ & $0.7540 \mathrm{wt} \%$ \\
\hline
\end{tabular}

\section{Blend Modification}

Recently, it is generally accepted that the introduction of polar groups in polyolefin compounds can greatly reduce the accumulation of space charge in insulation and reduce the probability of formation of electric tree branches and water branches. Zhang C [18 20] has study the space charge behaviors of LDPE blended with polypropylene copolymer (EP), find out that the blend polymer has a higher activation energy than LDPE and lower mobility of charges, and inhibited the migration of carrier by blending EP. These results suggest the polymer trap density and depth can be increased by blending EP. Yi Y [21, 22] modified XLPE by chlorinated polyethylene (CPE) as insulating material of DC cable, the relation of space charge densities with content of CPE is explored. It's shown that when the content of CPE is $1 \%$, the space charge decrease effectively and initiation voltage of short-circuit treeing increase. Zhimin D [23] use different weight ratio of ethylene-acrylic acid copolymer blending with XLPE to figure out its optimum content for decreasing space charge. It is found that the space charge effect is effectively decreased and the behaviors of both electrical treeing and water treeing in the samples are improved by test results. In order to study the electrical properties of LDPE/EVA composites, foreign scholars blend LDPE with EVA by different methods. It is found that the heterocharge decreased with the increase of EVA content, and the dielectric properties of composite material is improved [24, 25].

As a semi-crystalline polymer, the crystalline state of polyethylene directly affects the microstructure of polymer. It is well known that the microstructure strongly affects space charge behavior of insulating polymers. Xia W $[26,27]$ blend metallocene catalyzed polyethylene (MPE) 
with LDPE in order to research the influence of crystalline to the space charge distribution. It is showed in Tab.2, MPE acting as nucleator, can probably be attributed to the improvement of nucleation, and decrease of the size of spherulite. After calculation, sizes of sample LDPE, 1\%MPE, $3 \% \mathrm{MPE}, 5 \% \mathrm{MPE}$ are as follows: $3.78 \mu \mathrm{m}, 2.46 \mu \mathrm{m}, 3.78 \mu \mathrm{m}, 2.83 \mu \mathrm{m}, 3.48 \mu \mathrm{m}$. Test results show that the effectively decrease of space charge in the blends in the LDPE by blending $1 \mathrm{wt} \%$ MPE.

\section{Inhibition Mechanism of Space Charge}

It is universally received that adding nano-particles can format lots of deep traps for trapping charges, limiting charge movement and prevent the concentration of local charge. However, Demin $\mathrm{T}$ [28] pointed out that according to this interpretation, the space charge is not eliminated and they are still in the medium. Even if the distribution of space charge is uniform, in fact, it is contrary to the principles of electrical field calculated out by Poisson equation. Therefore, the formation and suppression mechanisms to explain the space charge by energy band theory of polymeric dielectric.

It is well known that grating functional monomers onto PE chains can format deep traps to limit charge mobility and make sure the space charge distribution evenly. Suh K S [12 17] and his team find that for MA, EA and nBA, space charge increase at first and then decreases as monomer graft ratio increasing, for $\mathrm{AA}, \mathrm{MAH}$ and $\mathrm{VP}$, space charge decreases with the increase of graft ratio. These changes is attributed to the combined effects of alkoxy groups acting as electron donating species and carbonyls and ring structure acting as a charge trapping sites. Besides, the microstructure of the polymer synthesized by grafting technology is uniform and regular, which ensures the uniformity of the electric field distribution of the insulator.

The introduction of polar substances such as CPE and EAA into the polymer through blending technology route, which has two competing effects: (1) increasing charge traps, restraining ionization charge migration, restraining space charge formation, and improving dielectric properties; (2) promoting non-polar impurity ionization in the polymer and the carrier increases. Therefore, there is an optimum content for suppressing the space charge by blending modification [21 23]. The technical route of blending modification with nucleation substances such as MPE and HDPE is a new method, which is intended to explore the inhibition of space charge effect from the aspects of changing the crystal form of polyethylene, reducing the crystal size and reducing the formation of grain boundary defects such as voids, cracks and dislocation [26 27].

\section{Conclusion}

The blending modification has the effect of increasing the charge traps, but the polar substances will produce a large number of polar small molecules, introduce a large amount of space charge, and lead to reduce polymer regularity during the crosslinking process. Therefore, the blending modification is mainly used to improve the aging resistance, flame retardant properties and basic mechanical properties of materials. But for improving the electricity properties of DC cable insulation materials, it is common to use a modified method of adding nano particles or grafting special functional groups. Both of them can provide charge trapping sites, and the graft ratio is another important factor affecting insulation space charge behavior. For using of additives, due to the size effect of nano particles, it is also necessary to deal with the problem of agglomeration. For grafting technique, the special functional group will acting as electron donating species. Nowadays, State Grid Corporation of China is also developing DC 500kV submarine cable by various methods. The advantages and disadvantages of different insulation material modification techniques will be verified in the process of cable manufacture by testing and engineering applications. 


\section{References}

[1] Jin G, Xiaohua W , Xuguang L, et al. Simulation of Electric Field and Temperature Field in 30kV DC XLPE Cable [J], Electric wire \& cable, 2009,6:9-12.

[2] Wei Z, Qinlin M, Jingjing Y, et al. Effects of DC Cable Shielding Materials on Space Charge in XLPE Insulation[J], Southern Power System Technology, 2015,9(10):19-25.

[3]Benhong O, Kangkang Z, et al. Influence of Aging Mode on Space Charge Distribution of AC XLPE Cables[J], High Voltage Engineering, 2012,38(08): 2123-2128.

[4]Ping Z, Design on the Insulation of the DC Cable [J], High Voltage Engineering, 2004, 30(8):2024.

[5]Xi C , Xia W, Kai W, et al. Temperature Gradient Effect on Distortion of DC Electrical Field in Polyethene[J], Journal of Xi'AN JiaoTong University, 2010,4(44):62-65.

[6]Xiaojuan J, Yun J, Yi Y et al. A demonstration Project of Flexible DC Power Transmission in Shanghai Nanhui Wind Power Sation[J], High Voltage Engineering. 2015,41(4):1132-1139.

[7]Zhengzheng C, Jiangkang Z, Benhong O, et al. The Difference of Insulation Characteristics between DC and AC Crossing-linked Polyethylene Cable and Its Mechanism Analysis[J], High Voltage Engineering. 2014,9(40): 2644-2652.

[8]Jinliang H, bin D, Yao Z, et al. Research Progress and Key Technology of Extruded HVDC Cable [J], High Voltage Engineering. 2015,41(5): 1417-1429.

[9] Chen X, Wang X, Wu K, et al. Modified Low Density Polyethylene by Nano-fills as Insulating Material of DC Cable( I )[J] High Voltage Engineering, 2012,10(38):2691-2697.

[10] Kai W, Xi C, Xia W, et al. Modified Low Density Polyethylene by Nano-fills as Insulating Material of DC Cable( II )[J] High Voltage Engineering, 2013,1(39):8-16.

[11] Gabriele P, Milano A, Enrico L. Electrical Cable for High Voltage Direct Current Transmission, and Insulating Composition: US, 8257782B2[P]. Sep 04, 2001

[12] Suh K S, Lee C R, Zhu Y, et al. Electrical properties of chemically modified polyethylenes[J]. IEEE transactions on dielectrics and electrical insulation, 1997, 4(6): 681-687.

[13] Lee C R, Kim O, Suh K S. Control of space charge in polyethylene by chemical modification[C]//Proceedings of Conference on Electrical Insulation and Dielectric PhenomenaCEIDP'96. IEEE, 1996, 1: 133-136.

[14] Lee C R, Okamoto T, Kanegami M, et al. Space charge behavior and electrical breakdown phenomena of acrylate-graft-polyethylenes[C] Electrical Insulating Materials, Proceedings of 1998 International Symposium on. IEEE, 1998: 207-210.

[15] Suh K S, Yoon H G, Lee C R, et al. Space charge behavior of acrylic monomer-grafted polyethylene[J]. IEEE transactions on dielectrics and electrical insulation, 1999, 6(3): 282-287.

[16] Lee S H, Park J K, Han J H, et al. Space charge and electrical conduction in maleic anhydridegrafted polyethylene[J]. IEEE transactions on dielectrics and electrical insulation, 1995, 2(6): 11321139.

[17] Suh K S, Kim J E, Oh W J, et al. Charge distribution and conduction characteristics of 2vinylpyridine-grafted polyethylenes[J]. Journal of Applied Physics, 2000, 87(10): 7333-7337.

[18] Zhang C, Mizutani T, Kaneko K, et al. Decay of space charge in LDPE and its blend polymer[J]. Journal of Physics D: Applied Physics, 2002, 35(15): 1875. 
[19] Zhang C, Mizutani T, Kaneko K, et al. Space charge behaviors of low-density polyethylene blended with polypropylene copolymer[J]. Polymer, 2002, 43(8): 2261-2266.

[20] Zhang C, Mizutani T, Kaneko K, et al. Space charge and conduction in LDPE-polypropylene copolymer blends[C]//Electrical Insulation and Dielectric Phenomena, 2001 Annual Report. Conference on. IEEE, 2001: 28-31.

[21]Yi Y, Demin T, Zhenfen G, et al. Modified Cross-Linked Polyethylene by Chlorinated Polyethylene as Insulating Material of DC Cabel [J].Proceedings of The Chinese Society for Electrical Engineering, 2000, 15(6): 50-55.

[22] Yi Y, Demin T, Qiangguo D, et al. Distribution and effect of space charge on dielectric properties in modified XLPE by chlorinated polyethylene[C], Properties and Applications of Dielectric Materials, 2000. Proceedings of the 6th International Conference on IEEE, 2000, 1: 268271.

[23] Zhimin D, Jie K, Demin T , et al. Relationships of space charge accumulation with electrical and water treeing in XLPE modified by EAA[J]. Proceedings of The Chinese Society for Electrical Engineering

[24] Suh K S, Kim J Y, Lee C R, et al. Charge distribution in polyethylene/ethylene vinylacetate laminates and blends[J]. IEEE transactions on dielectrics and electrical insulation, 1996, 3(2): 201206.

[25] Borhani M, Mirjalili G, Ziaie F, et al. Electrical properties of EVA/LDPE blends irradiated by high energy electron beam[J]. Nukleonika, 2007, 52(2): 77-81.

[26]Xia W, He Qin W, Demin T, et al. Space Charge Distribution and Crystalline Structure in LowDensity Polyethylene Modified by Metallocene Catalyzed Polyethylene[J]. Transactions of China Electrotechnical Society, 2006, 21(4): 35-40.

[27] Xia W, Caoyi W, Huaqin H, et al. Study on Mechanism of Space Charge in Low Density Polyethylene Modified by Metallocene Catalyzed Polyethylene [J]. Proceedings of The Chinese Society for Electrical Engineering.

[28] DeMin T, Xia W, ZePeng L, et al. Formation and inhibition mechanisms of space charges in direct current polyethylene insulation explained by energy band theory[J], Acta Physica Sinica 2012,61(1):017104-1-017104-7. 